\title{
Studies on the Utilization of $\mathrm{Zr}-2.5 \mathrm{Nb}$ Alloy Scrap for the Reclamation of Zirconium and Niobium Metals
}

\author{
R.H.Rakhasia, P.K.Tripathy", R.C.Hubli, V.H.Bafna and A.K.Suri \\ Materials Processing Division, Bhabha Atomic Research Centre, Trombay, \\ Mumbai-400085, India.
}

(Received January 6, 2004)

\begin{abstract}
A chemical processing scheme has been successfully applied to separate niobium and zirconium from $\mathrm{Zr}$ $2.5 \% \mathrm{Nb}$ alloy scrap, generated from nuclear industry. The processing route essentially comprised of two broad unit operations, viz. (i) chlorination of the alloy scrap to form mixed chlorides $\left(\mathrm{ZrCl}_{4}+\mathrm{NbCl}_{5}\right)$ and (ii) separation of the mixed chlorides by (a) hydrogen reduction and (b) salt scrubbing. It was possible to convert the scrap to $99.8 \mathrm{wt} \%$ pure $\mathrm{ZrCl}_{4}$ and $\mathrm{NbCl}_{5}$. Also, the niobium content in zirconium tetrachloride could be decreased to a value less than $1 \mathrm{wt} . \%$. While both the separating processes have been found effective for the removal of niobium to a low value, the latter process has been found to give better results consistently.
\end{abstract}

\section{INTRODUCTION}

$\mathrm{Zr}-2.5 \mathrm{Nb}$ alloy is being used as the standard pressure/coolant tube material in pressurized heavy water based nuclear power reactors. This alloy offers an ideal combination of properties, such as (i) better neutron economy as well as strength, (ii) higher corrosion and in-reactor creep resistance /1/. The wall thickness of these pressure tubes is deliberately kept low (between 0.0032 to $0.0049 \mathrm{~m}$ ) with a view to reducing the neutron loss by parasitic capture. During fabrication of these pressure/coolant tubes, large quantities of alloy scrap are generated. Although this scrap, obtained after the fabrication operation, is contaminated with interstitials $/ 2 /$, it is low in hafnium and high in niobium contents (Table 1) and hence can be a useful material for recycling, from the point of view of economic necessity. Keeping in view the two contradictory facets, viz. (i) the huge market for zirconium, niobium and their compounds/alloys /3-4/ and (ii) dwindling primary resources (minerals/ore bodies) for these two metals, it becomes all the more prudent to process this scrap, which is being generated in tonnage quantities, for augmenting the production of these two metals and their compounds/alloys.

The choice of an appropriate processing scheme depends upon the chemical nature of the scrap, obtained after the fabrication stage. Depending upon the fabrication parameters, either heavy or light scrap is generated. Heavy scrap, which is low in interstitial (nitrogen and oxygen) contents, can be re-melted, either directly or after appropriate blending (with relatively pure/fresh alloy) by vacuum arc melting. The light scrap, which is heavily contaminated with the interstitial impurities, cannot be re-melted directly as these interstitials form stable compounds with zirconium and remain with the alloy during subsequent melting and casting operations $/ 4 /$, thus necessitating the adoption of a suitable chemical processing scheme.

\footnotetext{
*pkt@magnum.barc.ernet.in
} 
Table 1

Chemical analysis of the as-received

$\mathrm{Zr}-2.5 \mathrm{Nb}$ alloy scrap

\begin{tabular}{|c|c|}
\hline Element & Amount (ppm) \\
\hline Aluminium & 10 \\
Boron & 0.5 \\
Cadmium & 0.5 \\
Calcium & 15 \\
Carbon & 125 \\
Chlorine & 0.5 \\
Chromium & 80 \\
Cobalt & 5 \\
Copper & 5 \\
Hafnium & 100 \\
Hydrogen & 5 \\
Iron & 1500 \\
Lead & 15 \\
Magnesium & 20 \\
Manganese & 3 \\
Molybdenum & 25 \\
Nickel & 60 \\
Niobium & 25,300 \\
Nitrogen & 150 \\
Oxygen & 10,000 \\
Tin & 180 \\
Titanium & 25 \\
Tungsten & 25 \\
Vanadium & 10 \\
\hline Balance (Zirconium), \% & 96.24 \\
\hline
\end{tabular}

Various processes, used for the recovery of zirconium from the contaminated/oxidized scraps, are (i) oxidation (ii) hydriding-dehydriding (iii) fused salt electrorefining and (iv) chlorination $15 \%$ Both the oxidation and hydriding-dehydriding routes can be used for the production of $\mathrm{Zr}-\mathrm{Nb}$ alloy powder. Although fused salt electrorefining is a suitable process for transforming impure zirconium to a state of high purity, this process cannot be applied to $\mathrm{Zr}-\mathrm{Nb}$ scrap for extracting zirconium, as niobium reacts with both the soluble zirconium salt as well as alkali/alkaline earth metal chlorides, present in the electrolyte, to form stable, complex and insoluble salts/complex compounds 16/. The process thus becomes unsuitable for the reclamation of these metals. Chlorination. on the other hand, offers a distinct possibility for recovering zirconium from a variety of alloys. Chemical processing involving chlorination is normally adopted to prepare zirconium-aluminium alloy, which is used as a cladding tube material for nuclear fuel rods/bundles. However, similar chlorination technique cannot be used for chlorinating $\mathrm{Zr}-2.5 \mathrm{Nb}$ scrap. The zirconium sponge, obtained by magnesiothermic reduction of mixed chlorides $\left(\mathrm{ZrCl}_{4}+\mathrm{NbCl}_{5}\right)$, has been found to be extremely hard to be chipped out of the Kroll vessel. Therefore, it becomes imperative to separate niobium pentachloride from zirconium tetrachloride, before carrying out the magnesiothermic reduction of $\mathrm{ZrCl}_{4}$ to produce zirconium sponge.

Two processes, namely, (i) hydrogen reduction of the mixed chlorides and (ii) salt scrubbing, have been investigated to separate $\mathrm{ZrCl}_{4}$ from $\mathrm{NbCl}_{5}$. During hydrogen reduction of the mixed chlorides, $\mathrm{NbCl}_{5}$ preferentially vapourizes and gets reduced to a mixture of $\mathrm{NbCl}_{3}$ and $\mathrm{NbCl}_{4}$ at a temperature of $673-723 \mathrm{~K}$, whereas $\mathrm{ZrCl}_{4}$ remains behind in the sublimer and thus does not get transformed to its lower halide(s). In the second process, both $\mathrm{ZrCl}_{4}$ and $\mathrm{NbCl}_{5}$ are made to react with $\mathrm{NaCl}$ to form respective hexachloro complexes, viz. $\mathrm{Na}_{2} \mathrm{ZrCl}_{6}$ and $\mathrm{NaNbCl}_{6}$ respectively $17 /$. These two complexes have different decomposition temperatures, $750 \mathrm{~K}$ and $550 \mathrm{~K}$ respectively. Upon heating, $\mathrm{NaNbCl}_{6}$ gets decomposed, at a relatively lower temperature as compared to $\mathrm{Na}_{2} \mathrm{ZrCl}_{6}$, to $\mathrm{NaCl}$ and $\mathrm{NbCl}_{5} / 6 / . \mathrm{NbCl}_{5}$, owing to relatively higher vapour pressure, preferentially gets condensed in a condenser, leaving behind $\mathrm{Na}_{2} \mathrm{ZrCl}_{6}$ in the reactor.

The present work describes the detailed experimental work, pertaining to chlorination of the alloy scrap followed by its separation into individual chlorides both by hydrogen reduction and salt scrubbing processes. Various experimental parameters have been optimized to achieve optimum separation.

\section{EXPERIMENTAL}

\subsection{Materials}

2.1.1. $\mathrm{Zr}-2.5 \mathrm{Nb}$ scrap, in the form of turnings/rods, was supplied by Nuclear Fuel Complex, Hyderabad, India. 
2.1.2. Commercially available chlorine cylinder was procured from M/s Standard Alkali, Navi Mumbai, Mumbai. India.

2.1.3. High purity hydrogen gas, IOLAR-2 grade, was supplied by M/s Indian Oxygen Ltd., Mumbai

2.1.4. Anhydrous $\mathrm{NaCl}$ crystal (GR grade) was procured from E-Merck (India) Ltd., Mumbai.

\subsection{Equipment}

\subsection{Chlorination}

The chlorination was carried out in a $0.04 \mathrm{~m}$ diameter quartz reactor (Figure 1). One end of the reactor was closed while the other end was provided with a cone-socket arrangement. The upper end of the reactor was connected (through the cone-socket arrangement) to a primary condenser, which, in turn, was connected to another (secondary) condenser. The pelletized (to $0.014 \mathrm{~m}$ diameter) scrap turnings were kept on quartz wool, which, in turn, was spread over the (perforated) bottom end of the reactor.

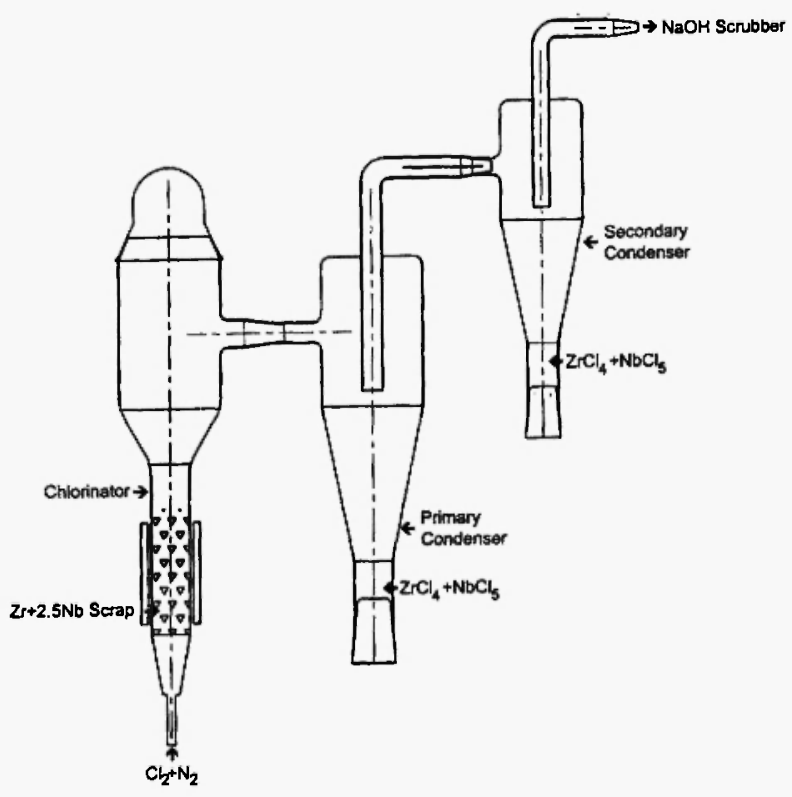

Fig. 1: Chlorination experimental assembly

\subsubsection{Hydrogen reduction reactor}

The experimental set up (Figure 2) consisted of a (i) $0.5 \times 10^{-3} \mathrm{~m}^{3}$ glass (Borosil) sublimer (ii) glass (Borosil) tube, having a cone-socket arrangement on one side (iii) horizontal quartz reactor $(0.03 \mathrm{~m}$ dia. and $0.6 \mathrm{~m}$ long), with a cone-socket arrangement on both sides and (iv) a cyclone condenser, made of glass (Borosil).

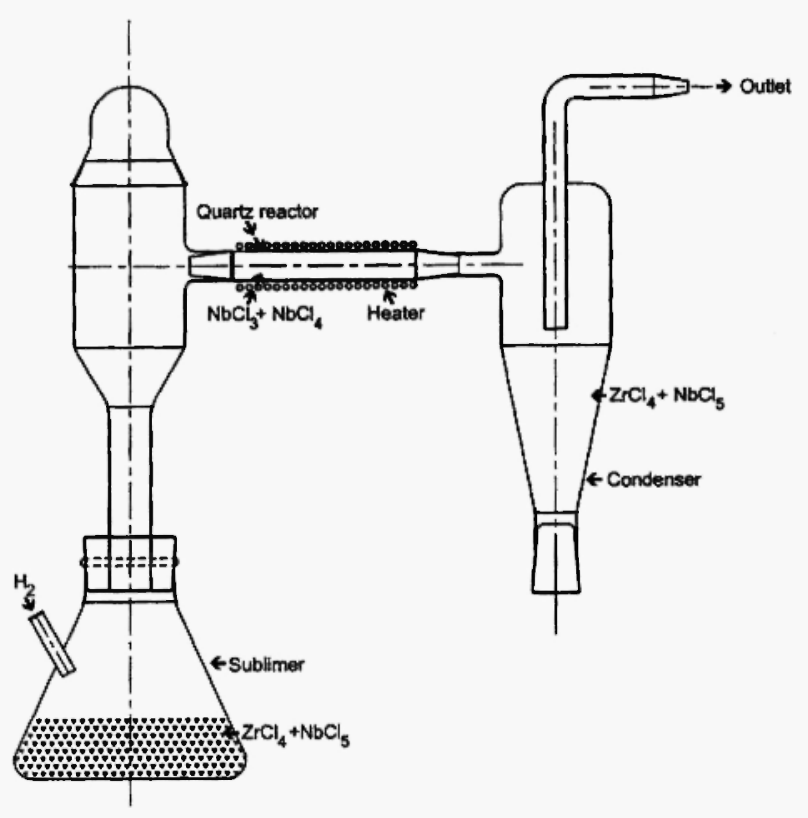

Fig. 2: Hydrogen reduction experimental setup

\subsubsection{Salt scrubber}

The salt scrubbing experimental set up (Figure 3) consisted of (i) $0.5 \times 10^{-3} \mathrm{~m}^{3}$ glass (Borosil) sublimer (ii) glass tube, with a cone-socket arrangement at one end and (iii) glass (Borosil) condenser. The glass tube, with a cone-socket arrangement, was connected to the condenser in a horizontal fashion.

\subsection{Procedure}

\subsection{Chlorination}

About $0.5 \mathrm{~kg}$ of the pelletized scrap was charged into the reactor. The charge was covered with alundum powder, which acted as a heat sink. The alundum covering was required to prevent the quartz reactor from possible damage from localized hot spots formed because of the high exothermicity of the chlorination 


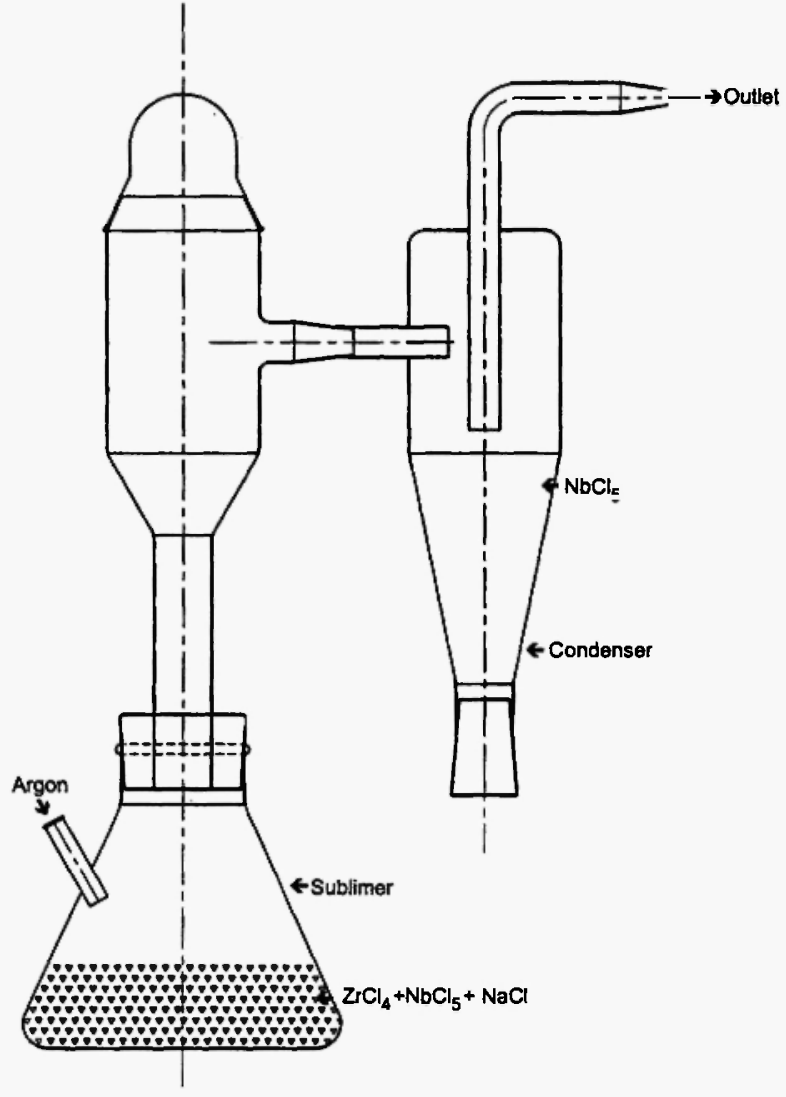

Fig. 3: Hexachlorocomplex formation and decomposition setup

reaction. The chlorinator was wound with heating tapes to provide external heating. Initially, the charge was heated under flowing argon atmosphere to about 573K. After that, the chlorine gas (along with argon) was introduced into the reactor. The temperature was monitored at different locations with the help of chromel-alumel thermocouple. The mixed chlorides, formed upon chlorination, were allowed to cool and condense in the condensers. The fractions obtained from both the condensers were remixed and preserved to carry out the subsequent separation studies.

\subsubsection{Hydrogen reduction}

The mixed chloride was kept in the sublimer. Before passing hydrogen gas, the sublimer, containing the mixed chloride, was flushed with high purity argon gas for about $\mathrm{l} h$. The temperature of the sublimer and the quartz reactor were gradually raised to $523 \mathrm{~K}$ under hydrogen flow. $\mathrm{NbCl}_{5}$, present in the mixture, got reduced to a mixture of $\mathrm{NbCl}_{4}$ and $\mathrm{NbCl}_{3}$, which remained in the condenser and reactor respectively, whereas $\mathrm{ZrCl}_{4}$ remained back in the sublimer along with traces of $\mathrm{NbCl}_{5}$. After the reaction was over, the sublimer was directly connected to the condenser, bypassing the reactor. The sublimer was then heated up to $723 \mathrm{~K}$ in order to (quantitatively) transfer $\mathrm{ZrCl}_{4}$ from the sublimer to the condenser, which was kept at room temperature. The chlorides, obtained from (i) sublimer (ii) quartz reactor and (iii) condenser were collected separately and preserved for analysis.

\subsubsection{Salt Scrubbing}

The $\mathrm{NaCl}$ was vacuum dried at $523 \mathrm{~K}$ for about $12 \mathrm{~h}$ prior to its use. Calculated quantities of $\mathrm{NaCl}$ were added to the mixed chlorides in a controlled atmosphere. The mixture was thoroughly mixed and then the contents were transferred to the glass sublimer. The sublimer was slowly heated to a temperature of $523 \mathrm{~K}$ and kept at that temperature for some time to ensure the completion of the formation of the respective hexachloro-complexes. The temperature was then raised to $573 \mathrm{~K}$, under argon atmosphere, to facilitate the decomposition of $\mathrm{NaNbCl}_{6}$ to $\mathrm{NbCl}_{5}$ and $\mathrm{NaCl}$. $\mathrm{NbCl}_{5}$ obtained upon thermal decomposition was transferred to the condenser whereas $\mathrm{Na}_{2} \mathrm{ZrCl}_{6}$ remained behind in the sublimer. Finally, $\mathrm{Na}_{2} \mathrm{ZrCl}_{6}$ was decomposed and collected in another condenser. The chlorides, from the sublimer and condenser, were collected and preserved for analysis.

\section{RESULTS \& DISCUSSION}

The three unit operations, namely, (i) chlorination of the alloy scrap (ii) hydrogen reduction of the mixed chlorides and (iii) complexation (of the mixed chlorides with sodium chloride)-decomplexation were found to be critically dependent upon a host of experimental parameters, such as time, temperature and gas flow rates etc.

\subsection{Chlorination}

The chlorination experiments were carried out in the 
temperature range of 573-773K. Although it was observed that the formation of mixed chlorides started at around $523 \mathrm{~K}$, the reaction did not undergo completion even if the temperature was raised to $573 \mathrm{~K}$. The quantitative conversion of the scrap to mixed chlorides was found to take place at a temperature $\geq 673 \mathrm{~K}$. The optimum parameters (for a charge of $100 \mathrm{~g}$ ) were: (i) chlorine flow rate $-0.16 \mathrm{~m}^{3} \mathrm{~s}^{-1}$ (ii) nitrogen flow rate $-0.16 \mathrm{~m}^{3} \mathrm{~s}^{-1}$ (iii) temperature $-673 \mathrm{~K}$ and (iv) duration $3 \mathrm{~h}$.

The primary separation of $\mathrm{NbCl}_{5}$ from $\mathrm{ZrCl}_{4}$ was achieved by maintaining the two condensers, primary and secondary respectively, at two different temperatures. The primary condenser was kept at $573 \mathrm{~K}$ whereas the secondary one was kept at room temperature. Mixed chlorides, collected in both the condensers, were analyzed for niobium contents. It was observed that the niobium contents in the primary and secondary condensers were $1 \mathrm{wt} . \%$ and $2.7 \%$ respectively. A little higher value of niobium content (2.7 wt.\% as compared to that of $2.5 \mathrm{wt} . \%$, present in the initial scrap) in the secondary condenser was observed probably because of the loss of $\mathrm{ZrCl}_{4}$. through the second condenser, to the scrubber. The mixed chlorides, condensed in both the condensers, were remixed thoroughly and the mixture was subjected to both hydrogen reduction as well as salt scrubbing studies.

\subsection{Hydrogen reduction of the mixed chlorides}

The mixture of the chlorides $\left(\mathrm{ZCl}_{4}+\mathrm{NbCl}_{5}\right)$ was subjected to hydrogen reduction at different temperatures, ranging from $573-723 \mathrm{~K}$, for various durations $(0.5-1.5 \mathrm{~h}$.) under different hydrogen flow rates $(100-150 \mathrm{cc} / \mathrm{min})$. The sublimer, containing the mixture of chlorides, was heated in the temperature range $373-523 \mathrm{~K}$ with a view to vapourizing the $\mathrm{NbCl}_{5}$ contents selectively. At about $473 \mathrm{~K}, \mathrm{NbCl}_{5}$ has appreciably higher vapour pressure as compared to that of $\mathrm{ZrCl}_{4}, 181.97 \mathrm{mmHg}$ and $3 \mathrm{mmHg}$, respectively. At around $673 \mathrm{~K}, \mathrm{NbCl}_{5}$ became selectively reduced, in the reactor, to a mixture of lower chlorides $\left(\mathrm{NbCl}_{4}\right.$ and $\mathrm{NbCl}_{3}$ ). The sublimation temperatures of $\mathrm{NbCl}_{4}$ and $\mathrm{NbCl}_{3}$ are $673 \mathrm{~K}$ and $923 \mathrm{~K}$ respectively. A greenishblack coloured crystal was obtained as residue (in the reactor), which was identified to be $\mathrm{NbCl}_{3}$. While traces of yellowish crystals of $\mathrm{NbCl}_{5}$ were deposited on the cooler zone of the reactor wall, a sizeable quantity of dark brown coloured $\mathrm{NbCl}_{4}$ were condensed in the condenser. Also, traces of tetrachloride were found to be deposited on the walls of the reactor. The reactor was then detached from the experimental assembly and another condenser was connected to the sublimer. The sublimer was then heated up to a temperature of $623 \mathrm{~K}$, the sublimation temperature of $\mathrm{ZrCl}_{4}$ being $604 \mathrm{~K}$, in order to transfer the (predominantly) $\mathrm{ZrCl}_{4}$ contents into the condenser. The analysis of the residue, collected from the sublimer, showed $99.6 \mathrm{wt} . \%$ zirconium and $0.2-0.35 \mathrm{wt} . \%$ niobium (Table 2), which indicated the fact that it was niobium pentachloride, that preferentially became reduced by hydrogen. Thus, the separation of $\mathrm{ZrCl}_{4}$ was achieved by selective reduction of $\mathrm{NbCl}_{5}$ (with hydrogen) followed by the distillation of residual $\mathrm{ZrCl}_{4}$.

The optimum conditions for achieving the separation of the mixed chlorides (on a $100 \mathrm{~g}$ scale), by hydrogen reduction, were: (i) temperature of the sublimer $-453 \mathrm{~K}$ (ii) temperature of the quartz reactor - 673K (iii) duration of reduction - $\mathrm{lh}$ and (iv) hydrogen flow rate $20.8 \mathrm{~m}^{3} \mathrm{~s}^{-1}$. Under optimum conditions, the purity and recovery of $\mathrm{ZrCl}_{4}$ were found to be $99.6 \mathrm{wt} . \%$ and 85 wt.\% respectively.

\subsection{Thermal decomposition of $\mathrm{NaNbCl}_{6}$ and $\mathrm{Na}_{2} \mathrm{ZrCl}_{6}$}

The formation of the sodium complexes, $\mathrm{NaNbCl}_{6}$ and $\mathrm{Na}_{2} \mathrm{ZrCl}_{6}$ respectively, and their subsequent thermal decomposition to their simple chlorides can be described by the following reactions.

\section{Formation}

$$
\begin{gathered}
\mathrm{NbCl}_{5}+\mathrm{NaCl}=\mathrm{NaNbCl}_{6} \\
\mathrm{ZrCl}_{4}+\mathrm{NaCl}=\mathrm{Na}_{2} \mathrm{ZrCl}_{6} \\
\text { Decomposition } \\
\mathrm{NaNbCl}_{6}=\mathrm{NbCl}_{5}+\mathrm{NaCl} \\
\mathrm{Na}_{2} \mathrm{ZrCl}_{6}=\mathrm{ZrCl}_{4}+\mathrm{NaCl}
\end{gathered}
$$

The decomposition temperatures of $\mathrm{NaNbCl}_{6}$ and $\mathrm{Na}_{2} \mathrm{ZrCl}_{6}$ are $56 \mathrm{IK}$ and $761 \mathrm{~K}$ respectively. Initially, the decomposition reaction was carried out at $573 \mathrm{~K}$, under continuous argon flow, with a view to ensuring the 
Table 2

Comparison of processes for the separation of $\mathrm{Zr}$ and $\mathrm{Nb}$ from the mixed chlorides, obtained from different locations

\begin{tabular}{|c|c|c|c|c|c|c|c|c|}
\hline \multirow{3}{*}{$\begin{array}{l}\begin{array}{l}\text { Process } \\
\text { description }\end{array} \\
\begin{array}{l}\text { Hydrogen } \\
\text { reduction }\end{array}\end{array}$} & \multirow{2}{*}{\multicolumn{2}{|c|}{ Operating temperature (K) }} & \multicolumn{6}{|c|}{ Analysis of $\mathrm{Zr}$ and $\mathrm{Nb}$ (wt.\%) from se parated chlorides } \\
\hline & & & \multicolumn{2}{|c|}{ Sublimer } & \multicolumn{2}{|c|}{$\begin{array}{l}\text { Quartz } \\
\text { reactor }\end{array}$} & \multicolumn{2}{|c|}{ Condenser } \\
\hline & $\begin{array}{l}\text { Sublimer } \\
\text { Reduction of } \mathrm{NbCl}_{5} \\
\end{array}$ & $\begin{array}{r}453 \\
673 \\
\end{array}$ & $\begin{array}{c}\mathrm{Zr} \\
99.6\end{array}$ & $\begin{array}{c}\mathrm{Nb} \\
0.2-0.35\end{array}$ & $\begin{array}{l}\mathrm{Zr} \\
6.4\end{array}$ & $\begin{array}{c}\mathrm{Nb} \\
93.5\end{array}$ & $\begin{array}{l}\mathrm{Zr} \\
1.3\end{array}$ & $\begin{array}{c}\mathrm{Nb} \\
98.5\end{array}$ \\
\hline Salt scrubbing & $\begin{array}{l}\text { Hexachloro complex formation } \\
\text { Decomposition of } \mathrm{NaNbCl}_{6}\end{array}$ & $\begin{array}{l}523 \\
573\end{array}$ & 99.8 & $0.12-0.15$ & - & - & 0.005 & 99.8 \\
\hline
\end{tabular}

Table 3

Chemical analysis of $\mathrm{ZrCl}_{4}$ and $\mathrm{NbCl}_{5}$, obtained after salt scrubbing

\begin{tabular}{|c|c|c|}
\hline \multirow[t]{2}{*}{ Element } & \multicolumn{2}{|c|}{ Amount (ppm) } \\
\hline & $\mathbf{N b C l}_{5}$ & $\mathrm{ZrCl}_{4}$ \\
\hline Aluminium & 50 & 50 \\
\hline Boron & 0.5 & 0.5 \\
\hline Cadmium & 0.5 & 0.5 \\
\hline Calcium & 50 & 40 \\
\hline Carbon & 125 & 125 \\
\hline Chlorine & 15 & 20 \\
\hline Chromium & 80 & 80 \\
\hline Cobalt & 20 & 15 \\
\hline Copper & 10 & 25 \\
\hline Hafnium & 100 & 100 \\
\hline Hydrogen & 5 & 25 \\
\hline Iron & 580 & 600 \\
\hline Lead & 25 & 25 \\
\hline Magnesium & 90 & 30 \\
\hline Manganese & 20 & 10 \\
\hline Molybdenum & 25 & 25 \\
\hline Nickel & 50 & 25 \\
\hline Niobium & - & 1200 \\
\hline Nitrogen & 110 & 100 \\
\hline Oxygen & - & - \\
\hline Tin & 180 & 150 \\
\hline Titanium & 10 & 25 \\
\hline Tungsten & 25 & 25 \\
\hline Vanadium & 10 & 10 \\
\hline Zirconium & 50 & - \\
\hline
\end{tabular}

complete decomposition of $\mathrm{NaNbCl}_{6}$. After that, a new condenser was attached to the sublimer and the temperature of the sublimer was gradually raised to $773 \mathrm{~K}$ in order to ensure the quantitative transfer of $\mathrm{ZrCl}_{4}$ vapour to the condenser. For $100 \mathrm{~g}$ of mixed chloride, it was possible to complete the thermal decomposition reaction within a duration of $\mathrm{l} h$.

The chloride samples collected in the sublimer and individual condensers were analyzed by (i) wavelength dispersive X-ray fluorescence and (ii) conventional DC Arc spectrography. The chlorides were first dissolved in water and then precipitated out from the solution by adding ammonium hydroxide to the solution. The respective hydroxides were then calcined at $1173 \mathrm{~K}$ to their corresponding oxides, i.e. $\mathrm{ZrO}_{2}$ and $\mathrm{Nb}_{2} \mathrm{O}_{5}$ respectively. The detailed compositional analysis of the purified $\mathrm{ZrCl}_{4}$ and $\mathrm{NbCl}_{5}$ has been provided in Tables 2 and 3.

It was observed that from an operational point of view, salt scrubbing was much simpler as compared to the hydrogen reduction process. Besides, the former process also yielded better separation factors in a consistent manner.

\section{MERITS OF THE PRESENT PROCESS}

The notable advantages of the present process are: (i) a smaller number of unit operations is needed: (ii) the possibility of obtaining highly pure metal 
chlorides/oxides which can be directly taken up, without subjecting them to any purification scheme, as the starting material(s) for the production of the respective metals /8/; (iii) comparatively faster process chemistry as compared to both hydriding-de-hydriding and (iv) economic viability. Among its limitations, this process requires careful handling of both $\mathrm{ZrCl}_{4}$ and $\mathrm{NbCl}_{5}$, as these salts are extremely hygroscopic. Besides, they react with moisture/water vapour to release hydrochloric acid fumes. That is why it is mandatory to avoid skin contact with these compounds, and store them carefully, preferably in a dry area.

\section{CONCLUSION}

The present study has shown the technical feasibility of recovering both zirconium and niobium from its scrap, $\mathrm{Zr}-2.5 \mathrm{Nb}$. A chemical processing route, consisting of chlorination of the alloy scrap, followed by the separation of the constituent chlorides either by hydrogen reduction or by salt scrubbing of the mixed chlorides, has been found to be quite attractive in terms of the simplicity of the overall process, relatively faster process chemistry, better achievable purity as well as recovery of the individual chlorides. Among hydrogen reduction and salt scrubbing processes, the latter has been found to give better separation efficiency in a consistent manner.

\section{ACKNOWLEDGEMENTS}

The authors place on record their sincere thanks to Dr. J.C. Sehra and Mr. V.D. Shah for their help and suggestions in carrying out the present piece of investigation.

\section{REFERENCES}

I. B.M. Ma, Nuclear Reactor Materials and Applications, Van Nostrand Reinhold Co., NY, 1983; pp. 282-301.

2. C.V. Sundaram, S.P. Garg and J.C. Sehra, Refining of refractory metals, Int. Conf. on Metal Sciences The Emerging Frontiers, T.R. Anantharaman, S.L. Malhotra, S. Ranganathan and P. Ramarao (Eds.), Proc. Int. Conf., Varanasi, 1977; pp. 351-367.

3. C.K. Gupta and A.K. Suri, Extractive Metallurgy of Niobium, CRC Press, Florida, USA, 1994; p. 183.

4. Zirconium-2002 [Zirc-02], Proceedings of the Symposium, P.K. De (Ed.), September 11-13, 2002, Bhabha Atomic Research Centre, Trombay, Mumbai, India, pp. 1-231.

5. J.C. Sehra and D.K. Bose, Proc. Int. Conf. Minerals and Metal Industries Waste Utilization, Bhubaneswar, 1996.

6. S.N. Flengas, G.J. Kipouros and P.T. Tumidajski, Metals Materials and Processes, 2 (3), ISI (1990).

7. J.H. Canterford and R. Cotton, Halides of Second and Third Transition Metals, Wiley-Interscience Publication, London. 1968; pp. 28-68.

8. G.L. Miller, Tantalum and Niobium, Butterworth Scientific Publications, 1959; pp. 69-243. 
